\title{
Artigo/Article
}

\section{Polimorfismos do gene NRAMP1 em indivíduos com reações hansênicas, atendidos em dois Centros de Referência no Recife, nordeste do Brasil}

\author{
NRAMP1 gene polymorphisms in individuals with leprosy reactions attended at two reference \\ centers in Recife, northeastern Brazil
}

Márcia Almeida Galvão Teixeira ${ }^{1}$, Norma Lucena Silva ${ }^{2}$, Alessandra de Luna Ramos ${ }^{2}$, Ana Hatagima ${ }^{3}$ e Vera Magalhães $^{4}$

\begin{abstract}
RESUMO
Introdução: Para investigar susceptibilidade às reações hansênicas, três polimorfismos do gene natural resistance-associated macrophage protein (NRAMP1), foram determinados em 201 indivíduos, atendidos em dois centros de referência no Recife, entre 2007 e 2008, sendo 100 paucibacilares e 101 multibacilares. Métodos: A determinação dos polimorfismos 274C/T, D543N e 1729+55del4 do gene NRAMP1 foi realizada utilizando a técnica do polimorfismo de fragmento de restrição em DNA extraído de sangue periférico e as estimativas das freqüências alélicas e genotípicas foram feitas por contagem direta. Resultados: Os genótipos predominantes foram: CC (51,8\%) para 274C/T, GG (86,6\%) para D543N e+-TGTG (59,9\%) para 1729+55del4. O genótipo mutante $274 \mathrm{~T}$ predominou na negatividade da reação reversa $(\mathrm{p}=0,03)$ e na positividade do eritema nodoso $(\mathrm{p}=0,04)$. Conclusões: Nossos resultados sugerem que o polimorfismo $274 \mathrm{C} / \mathrm{T}$ do gene NRAMP1 pode auxiliar na determinação da susceptibilidade à reação tipo II em indivíduos com hanseníase.

Palavras-chaves: Hanseníase. Polimorfismo de fragmento de restrição.
\end{abstract}

\begin{abstract}
Introduction: To investigate susceptibility to leprosy reactions, three polymorphisms of the natural resistance-associated macrophage protein (NRAMP1) gene were determined in 201 individuals who were attended at two reference centers in Recife, between 2007 and 2008. Of these, 100 were paucibacillary and 101 were multibacillary. Methods: The 274C/T, D543N and 1729+55del4 polymorphisms of the NRAMP1 gene were determined using the technique of restriction fragment polymorphism on DNA extracted from peripheral blood. Allelic and genotypic frequencies were estimated by direct counting. Results: The predominant genotypes were: CC (51.8\%) for 274C/T; GG (86.6\%) for D543N; and +-TGTG (59.9\%) for $1729+55$ del 4 . The mutant genotype $274 \mathrm{~T}$ predominated in negativity of the reverse reaction $(\mathrm{p}=0.03)$ and in positivity of erythema nodosum leprosum $(\mathrm{p}=0.04)$. Conclusions: Our results suggest that $274 \mathrm{C} / \mathrm{T}$ polymorphism of the NRAMP1 gene may aid in determining the susceptibility to type II reactions among leprosy patients.
\end{abstract}

Key-words: Leprosy. Restriction fragment polymorphism.

\footnotetext{
1. Faculdade de Ciências Médicas, Universidade de Pernambuco, Policlínica Lessa de Andrade, Recife, PE. 2. Laboratório de Biologia Molecular, Instituto de Medicina Integrada Prof. Fernando Figueira de Pernambuco, Recife, PE. 3. Laboratório de Genética Humana, Instituto Oswaldo Cruz, Fundação Oswaldo Cruz. Rio de Janeiro, RJ. 4. Disciplina de Doenças Infecciosas e parasitárias, Faculdade de Medicina da Universidade Federal de Pernambuco, Recife, PE

Endereço para correspondência: Dra. Márcia Almeida Galvão Teixeira. FCM/UPE. Rua Jornalista Guerra de Holanda 158/1102, Casa Forte, 52061-010 Recife, PE.

Tel: $55813427-2268$

e-mail: marciateixeira@folha.rec.br

Recebido para publicação em 05/10/2009

Aceito em 05/03/2010
}

\section{INTRODUÇÃO}

A hanseníase é uma doença complexa, cujo desfecho resulta de uma combinação entre a ação do Mycobacterium leprae, fatores ambientais, socioeconômicos e a predisposição individual ${ }^{1}$.

O número global de casos de hanseníase tem mostrado tendência de declínio desde o ano de 2001, exceto em regiões da África e no Brasil, as quais mantêm alta endemicidade ${ }^{2}$.

As reações hansênicas são fenômenos de hipersensibilidade a antígenos do Mycobaterium leprae $^{3}$. Os principais tipos de reação são: a reação reversa (tipo I) e o eritema nodoso hansênico (tipo II). A reação tipo I pode estar presente em indivíduos com as formas clínicas paucibacilares ou multibacilares, enquanto a reação tipo II acomete pacientes multibacilares ${ }^{4}$.

Os episódios reacionais estão presentes em cerca de $10 \%$ a $50 \%$ dos pacientes, predominando nas formas clínicas multibacilares. Geralmente surgem durante o tratamento, entre o segundo e sexto mês, mas podem ocorrer antes ou após a terapêutica e são responsáveis por sequelas importantes e dificultam o diagnóstico diferencial com a recidiva da doença, e, portanto, a conduta terapêutica ${ }^{5}$.

A teoria que admite que a incapacidade de destruição dos bacilos de Hansen pelos macrófagos pode ser influenciada por polimorfismos gênicos tende a ganhar força nos últimos anos ${ }^{6,7}$. Tem-se postulado que um conjunto de genes pode modificar a susceptibilidade à hanseníase e às diferentes formas clínicas $^{1,7-10}$.

Ferreira e cols ${ }^{9}$, estudando o polimorfismo (GT) $\mathrm{n}$ do NRAMP1, observaram que os indivíduos com resposta negativa à lepromina, ou seja, Mitsuda negativos, que expressavam um determinado tipo de alelo desse polimorfismo, apresentavam sete a oito vezes mais chances de desenvolver a hanseníase, concluindo haver relação entre variações polimórficas e susceptibilidade à doença. 
Assim, também, o gene da proteína 1 associada à resistência natural do macrófago (natural resistance associated macrophage protein 1 - NRAMP1) tem sido relacionado à defesa inata, bem como à adquirida, que confere resistência a parasitas intracelulares, por sua atividade estar diretamente ligada ao processamento dos antígenos bacterianos pelas células fagocitárias ${ }^{11,12}$.

O gene da NRAMP1 localiza-se na região $2 \mathrm{q} 35$ do cromossoma 2 e a proteína codificada por ele é detectada no compartimento lisossomal de macrófagos, monócitos e leucócitos periféricos, como também no fígado, baço e pulmões, após indução por linfocinas e produtos bacterianos ${ }^{13,14}$, exercendo a função de uma bomba de efluxo de cátions divalentes, como $\mathrm{Fe}^{++}$e $\mathrm{Mn}^{++15,16}$. A remoção destes íons, essenciais para a sobrevivência do microorganismo no macrófago, resulta em restrição da multiplicação e propagação intracelular do patógeno, além de privar a bactéria da produção de enzimas protetoras (catalase e superóxido dismutase), que neutralizam a ação de componentes oxigênio reativos produzidos pelo macrófago ${ }^{16-18}$

Algumas mutações no gene NRAMP1 anulam a resistência natural a infecções por Mycobacteriae. Liu e cols ${ }^{19}$, investigando 80 indivíduos com tuberculose, descreveram nove polimorfismos, dentre eles o $274 \mathrm{C} / \mathrm{T}$, que decorre de uma troca de bases citosina (C) por timina $(\mathrm{T})$ na posição 274 do éxon 3, o polimorfismo $\mathrm{D} 543 \mathrm{~N}$, no qual há troca de bases guanina $(\mathrm{G})$ por adenina $(\mathrm{A})$ na posição 1703 do éxon 15 , e o terceiro polimorfismo $1729+55$ del4, no qual há deleção das bases TGTG na região 3' não traduzida (3'UTR). Concluíram que as variantes NRAMP1 podem ser úteis para análise genética da susceptibilidade humana à hanseníase, em analogia à verificada para parasitoses intracelulares, porque esses polimorfismos são importantes reguladores das vias de diferenciação de macrófagos.

Meisner e cols ${ }^{20}$ tomando como base a associação entre polimorfismo da NRAMP1 e susceptibilidade à tuberculose, compararam a distribuição do polimorfismo $1729+55$ del 4 na hanseníase e observaram maior frequência de heterozigose entre multibacilares.

O objetivo deste artigo foi investigar a associação entre três polimorfismos do gene NRAMP1 e as reações hansênicas em pacientes multibacilares e paucibacilares.

\section{MÉTODOS}

\section{Amostra}

Realizou-se um estudo comparativo, observacional envolvendo 201 indivíduos hansenianos com quadro reacional, em tratamento ou após alta medicamentosa, excluída a forma neurítica pura de hanseníase, oriundos da demanda espontânea ou encaminhados por outros serviços da rede pública e acompanhados nos ambulatórios de hanseníase do Centro Integrado de Saúde Amaury de Medeiros (CISAM)/Universidade de Pernambuco e da Policlínica Lessa de Andrade, em Recife, nos anos de 2007 e 2008.

As reações hansênicas foram classificadas de acordo com os critérios de Ridley e Joppling ${ }^{21}$, em tipo I ou tipo II. O paciente com reação tipo I ou reversa caracterizava-se clinicamente por: infiltração de lesões antigas associadas ao surgimento de novas lesões em forma de manchas ou placas infiltradas, eritema, dor, lesões vésico-bolhosas, ulcerações, parestesia, mal-estar, febre, dor ou espessamento de nervos periféricos. Como reação tipo II ou eritema nodoso, considerou-se o quadro caracterizado pelo surgimento de nódulos disseminados, febre e neurite ${ }^{4}$.

Cem $(49,8 \%)$ pacientes eram paucibacilares, pois apresentavam baciloscopia inicial negativa antes do tratamento, menos de cinco lesões cutâneas e menos de um tronco nervoso afetado, enquanto que 101 (50,2\%) eram multibacilares, ou seja, tinham baciloscopia inicial positiva.

Otipodepelefoibaseadona classificaçãode Fitzpatrick ${ }^{22}$ que contempla a cor dos olhos, cabelos e da pele. Os tipos I, II e III corresponderam à pele branca, os tipos IV e V, à parda, e o tipo VI, à negra.

O protocolo constou de exame clínico dermatológico e realização de coleta de 7,5 ml de sangue venoso periférico, os quais foram enviados para o Laboratório de Imunopatologia do Instituto Aggeu Magalhães da FIOCRUZ, para extração do DNA genômico de leucócitos.

\section{Determinação dos polimorfismos}

A determinação dos polimorfismos foi realizada através da reação em cadeia da polimerase (PCR) seguida pela técnica do polimorfismo de fragmento de restrição (RFLP) proposto por Lui e cols ${ }^{17}$. A reação foi realizada em um total de $25 \mu \mathrm{L}$ contendo 50 ng a 100ng de DNA, Tris-HCL 10mM (pH 9.0), KCl 50mM, $\mathrm{MgCl}$ 1,5mM, 0,2mM de cada dNTP, 20pmol de cada iniciador e uma unidade de Taq DNA polymerase (Biotools, USA).

Os iniciadores utilizados (5' a 3') na PCR foram: TCGCACCATCCCTATACCCAGeTCTCGAAAGTGTCCCACTCAG para o polimorfismo $274 \mathrm{C} / \mathrm{T}$ e GCATCTCCCCAATTCATGGT e AACTGTCCCACTCTATCCTG para os polimorfismos D543N e $1729+55$ del 4 . As condições da reação foram: um ciclo inicial de $94^{\circ} \mathrm{C}$ por $3 \mathrm{~min}$, seguido de um protocolo com 35 ciclos a $94^{\circ} \mathrm{C}$ por $1 \mathrm{~min}$ para desnaturação, $60^{\circ} \mathrm{C}$ por $1 \mathrm{~min}$ para anelamento e $72^{\circ} \mathrm{C}$ por 1 min para extensão e um ciclo de extensão final de $72^{\circ} \mathrm{C}$ por $10 \mathrm{~min}$ no termociclador Gradient da Eppendorf. As amostras foram submetidas à amplificação do gene constitutivo GPDH como controle positivo de reação e verificação da qualidade do DNA extraído. Como controle negativo da reação, foram usados os reagentes da PCR, em ausência de DNA. O produto da amplificação foi visualizado em gel de agarose a $2 \%$ corado pelo brometo de etídeo $(0,5 \mu \mathrm{g} / \mathrm{mL})$, sob luz ultravioleta e fotografado com filme Polaroid 667.

A segunda etapa do ensaio constou de digestão enzimática de $5 \mu \mathrm{L}$ do produto da PCR, adicionados a uma solução preparada com tampão (1x) de reação NEBuffer4 (BioLabs, United Kingdom). Para o polimorfismo $274 \mathrm{C} / \mathrm{T}$ a PCR produziu fragmentos de 216 pares de bases (bp), os quais tratados pela enzima de restrição $\mathrm{MnlI}$ a $37^{\circ} \mathrm{C}$ durante 18 horas, definiram o alelo mutante $(\mathrm{T})$ correspondente aos fragmentos 167,37 e 12 bp e o alelo selvagem (C), correspondente aos fragmentos 102, 65, 37 e $12 \mathrm{bp}$. Para o polimorfismo D543N, os fragmentos com 240bp ou 244 bp foram submetidos à enzima de restrição Ava II, definindo o alelo mutante (A) correspondente aos fragmentos 201 e $39 \mathrm{bp}$ e o selvagem (G) correspondente aos fragmentos 126,79 e $39 \mathrm{bp}$. Os fragmentos do polimorfismo $1729+55 \mathrm{del} 4$, com $240 \mathrm{bp}$ ou $244 \mathrm{bp}$, foram submetidos à enzima de restrição Fok I definindo o alelo mutante (-TGTG), correspondente ao fragmento $240 \mathrm{bp}$, e o alelo selvagem (+TGTG), com os fragmentos 211 e $33 \mathrm{bp}$.

O produto da digestão foi visualizado em gel de poliacrilamida a $10 \%$ e corado pela prata. O gel foi secado em filme celofane e arquivado para determinação dos genótipos segundo o protocolo de Liu e cols ${ }^{19}$. 
Devido a dificuldades técnicas, a determinação dos polimorfismos 274 C/T e D543N foi possível nas amostras de DNA de 197 indivíduos (100 multibacilares e 97 paucibacilares), enquanto o polimorfismo $1729+55$ del 4 foi determinado nas amostras de 172 indivíduos ( 85 multibacilares e 87 paucibacilares).

A análise estatística foi realizada pelos programas MSOffice Excel versão 2003 para o gerenciamento do banco de dados; Statistical Package for Social Sciences (SPSS) for Windows versão 12.0, para a execução dos cálculos estatísticos, elaboração e edição de gráficos e MSOffice Word versão 2003, para elaboração das tabelas. Foram empregados o teste qui-quadrado (Mantel-Haenszel), para testar associação entre variáveis qualitativas, e o teste exato de Fisher, nos casos em que o valor esperado foi menor que cinco, ambos em nível de significância de 0,05 .

\section{Ética}

O projeto foi aprovado pelo Comitê de Ética do Centro Integrado de Saúde Amaury de Medeiros.

\section{RESULTADOS}

A amostra foi constituída em sua maioria por homens, indivíduos fototipo V, com idade entre 30-44 anos e procedentes de Recife (Tabela 1).

As distribuições das frequências alélicas e genotípicas de cada polimorfismo nos indivíduos reacionais multibacilares e paucibacilares foram verificadas. Os alelos C, G e +TGTG foram os mais frequentes para os polimorfismos $274 \mathrm{C} / \mathrm{T}$, D543N e 1729+ 55del4, respectivamente, independente da classe bacilar. Quanto aos genótipos, as maiores frequências foram observadas para CC, GG e +-TGTG. Não se observaram diferenças significantes na distribuição genotípica entre pacientes multibacilares, quando comparados aos paucibacilares (Tabela 2).
Na Tabela 3, estão apresentadas as distribuições das freqüências alélicas e genotípicas dos polimorfismos segundo sexo dos pacientes.

A distribuição dos polimorfismos segundo cor da pele, entre multibacilares e paucibacilares, encontra-se na Tabela 4, na qual não foram identificadas diferenças significantes. Os fototipos I,II e III formaram o grupo A e os fototipos IV,V e VI o grupo B.

Na Tabela 5, observa-se a distribuição dos genótipos segundo tipos reacionais. Foi possível identificar diferenças significantes relacionadas ao genótipo mutante 274 TT. Em pacientes com genótipo TT, a reação tipo I foi mais frequente e a reação tipo II foi mais frequente nos indivíduos sem o genótipo $\Pi$.

TABELA 1 - Distribuição das variáveis de caracterização dos 201 pacientes reacionais atendidos no CISAM e Policlínica Lessa de Andrade, 2007-2008.

\begin{tabular}{lcc}
\hline Variáveis & Número & Porcentagem \\
\hline Sexo & 131 & 65,2 \\
masculino & 70 & 34,8 \\
feminino & & \\
Cor da pele & 42 & 20,9 \\
fototipo III & 60 & 29,9 \\
fototipo IV & 74 & 36,8 \\
fototipo V & 25 & 12,4 \\
outros & & \\
Idade (anos) & 8 & 4,0 \\
$0-14$ & 40 & 19,9 \\
$15-29$ & 69 & 34,3 \\
$30-44$ & 61 & 30,4 \\
$45-59$ & 23 & 11,4 \\
$\geq 60$ & & 16,4 \\
Procedência & 129 & 64,2 \\
Recife & 39 & 19,4 \\
interior & 33 & \\
região metropolitana & & \\
\hline & & \\
& & \\
\hline
\end{tabular}

TABELA 2 - Distribuição das frequências alélicas e genotípicas dos polimorfismos 274 C/T, D543N e 1729+55del4 do gene NRAMP1 dos pacientes multibacilares e paucibacilares com reação hansênica.

\begin{tabular}{|c|c|c|c|c|c|c|c|c|}
\hline \multirow[b]{2}{*}{ Polimorfismo } & \multirow[b]{2}{*}{ Alelo/genótipo } & \multicolumn{2}{|c|}{ Multibacilares } & \multicolumn{2}{|c|}{ Paucibacilares } & \multicolumn{2}{|c|}{ Total } & \multirow[b]{2}{*}{$p$} \\
\hline & & $\mathrm{n}^{\mathrm{o}}$ & $\%$ & $\mathrm{n}^{\mathrm{o}}$ & $\%$ & $\mathrm{n}^{\mathrm{o}}$ & $\%$ & \\
\hline \multirow[t]{5}{*}{$274 \mathrm{C} / \mathrm{T}$} & $\mathrm{C}$ & 138 & 69,0 & 144 & 74,2 & 282 & 71,6 & 0,25 \\
\hline & $\mathrm{T}$ & 62 & 31,0 & 50 & 25,8 & 112 & 28,4 & \\
\hline & $\mathrm{CC}$ & 49 & 49,0 & 53 & 55,0 & 102 & 51,8 & 0,43 \\
\hline & $\mathrm{CT}$ & 40 & 40,0 & 38 & 39,0 & 78 & 39,6 & 0,91 \\
\hline & $\Pi$ & 11 & 11,0 & 6 & 6,0 & 17 & 8,6 & 0,23 \\
\hline \multirow[t]{4}{*}{ D543N } & G & 190 & 95,0 & 178 & 91,8 & 368 & 93,4 & 0,19 \\
\hline & A & 10 & 5,0 & 16 & 8,2 & 26 & 6,6 & \\
\hline & GG & 90 & 90,0 & 81 & 83,5 & 171 & 86,8 & 0,18 \\
\hline & GA & 10 & 10,0 & 16 & 16,5 & 26 & 13,2 & \\
\hline \multirow[t]{5}{*}{$1729+55$ del 4} & +TGTG & 99 & 58,2 & 104 & 59,8 & 203 & 59,0 & 0,77 \\
\hline & -TGTG & 71 & 41,8 & 70 & 40,2 & 141 & 41,0 & \\
\hline & ++TGTG & 24 & 28,2 & 26 & 29,9 & 50 & 29,1 & 0,81 \\
\hline & +-TGTG & 51 & 60,0 & 52 & 59,8 & 103 & 59,9 & 0,98 \\
\hline & —TGTG & 10 & 11,8 & 9 & 10,3 & 19 & 11,0 & 0,77 \\
\hline
\end{tabular}

Genótipos: cálculo do qui-quadrado comparativo de cada genótipo com a soma dos outros do mesmo polimorfismo. 
TABELA 3 - Distribuição das frequências alélicas e genotípicas de cada polimorfismo segundo baciloscopia e sexo dos pacientes.

\begin{tabular}{|c|c|c|c|c|c|c|c|c|c|c|c|}
\hline \multirow[b]{3}{*}{ Polimorfismo } & \multirow[b]{3}{*}{ Alelo/Genótipo } & \multicolumn{4}{|c|}{ Multibacilares } & \multirow[b]{3}{*}{$p$} & \multicolumn{4}{|c|}{ Paucibacilares } & \multirow[b]{3}{*}{$p$} \\
\hline & & \multicolumn{2}{|c|}{ masculino } & \multicolumn{2}{|c|}{ feminino } & & \multicolumn{2}{|c|}{ masculino } & \multicolumn{2}{|c|}{ feminino } & \\
\hline & & $\mathrm{n}^{\circ}$ & $\%$ & $\mathrm{n}^{\mathrm{o}}$ & $\%$ & & $\mathrm{n}^{\mathrm{o}}$ & $\%$ & $\mathrm{n}^{\mathrm{o}}$ & $\%$ & \\
\hline \multirow[t]{7}{*}{$274 \mathrm{C} / \mathrm{T}$} & $\mathrm{C}$ & 95 & 66,9 & 43 & 74,1 & 0,32 & 89 & 75,4 & 55 & 72,4 & 0,64 \\
\hline & $\mathrm{T}$ & 47 & 33,1 & 15 & 25,9 & & 29 & 24,6 & 21 & 27,6 & \\
\hline & $\mathrm{CC}$ & 32 & 45,0 & 17 & 58,6 & 0,22 & 33 & 55,9 & 20 & 52,6 & 0,75 \\
\hline & CT & 31 & 43,7 & 9 & 31,0 & 0,24 & 23 & 39,0 & 15 & 39,5 & 0.96 \\
\hline & $\mathrm{TT}$ & 8 & 11,3 & 3 & 10,4 & $1,00^{*}$ & 3 & 5,1 & 3 & 7,9 & $0,68^{*}$ \\
\hline & G & 136 & 95,8 & 54 & 93,1 & $0,48^{*}$ & 106 & 89,8 & 72 & 94,7 & 0,23 \\
\hline & A & 6 & 4,2 & 4 & 6,9 & & 12 & 10,2 & 4 & 5,3 & \\
\hline \multirow[t]{4}{*}{ D543N } & GG & 65 & 91,5 & 25 & 86,2 & $0,47^{*}$ & 47 & 79,7 & 34 & 89,5 & 0,21 \\
\hline & GA & 6 & 8,5 & 4 & 13,8 & & 12 & 20,3 & 4 & 10,5 & \\
\hline & +TGTG & 72 & 58,0 & 27 & 58,7 & 0,94 & 64 & 60,4 & 40 & 8,8 & 0,84 \\
\hline & -TGTG & 52 & 41,0 & 19 & 41,3 & & 42 & 39,6 & 28 & 41,2 & \\
\hline \multirow[t]{3}{*}{$1729+55$ del 4} & ++TGTG & 16 & 25,8 & 8 & 34,8 & 0,42 & 17 & 32,1 & 9 & 26,5 & 0,58 \\
\hline & +-TGTG & 40 & 64,5 & 11 & 47,8 & 0,17 & 30 & 56,6 & 22 & 64,7 & 0,45 \\
\hline & —TGTG & 6 & 9,7 & 4 & 17,4 & $0,45^{*}$ & 6 & 1,3 & 3 & 8,8 & 0,73 \\
\hline
\end{tabular}

*Teste exato de Fischer. Genótipos: cálculo do qui-quadrado comparativo de cada genótipo com soma dos outros do mesmo polimorfismo.

TABELA 4 - Distribuição das frequências alélicas e genotípicas de cada polimorfismo segundo baciloscopia e fototipo dos pacientes.

\begin{tabular}{|c|c|c|c|c|c|c|c|c|c|c|c|}
\hline \multirow[b]{3}{*}{ polimorfismo } & \multirow[b]{3}{*}{ Alelo/genótipo } & \multicolumn{4}{|c|}{ Multibacilares } & \multicolumn{6}{|c|}{ Paucibacilares } \\
\hline & & \multicolumn{2}{|c|}{$\mathrm{A}^{*}$} & \multicolumn{2}{|c|}{$\mathrm{B}^{*}$} & \multirow[b]{2}{*}{$p$} & \multicolumn{2}{|c|}{$\mathrm{A}^{*}$} & \multicolumn{2}{|c|}{$\mathrm{B}^{*}$} & \multirow[b]{2}{*}{$p$} \\
\hline & & $\overline{\mathrm{n}^{\circ}}$ & $\%$ & $\mathrm{n}^{\mathrm{o}}$ & $\%$ & & $\mathrm{n}^{\mathrm{o}}$ & $\%$ & $\mathrm{n}^{\mathrm{o}}$ & $\%$ & \\
\hline \multirow[t]{5}{*}{$274 \mathrm{C} / \mathrm{T}$} & $\mathrm{C}$ & 27 & 79,4 & 111 & 66,9 & 0,15 & 46 & 74,2 & 98 & 74,2 & 0,99 \\
\hline & $\mathrm{T}$ & 7 & 20,6 & 55 & 33,1 & 0,38 & 16 & 25,8 & 34 & 25,8 & \\
\hline & $\mathrm{CC}$ & 10 & 58,8 & 39 & 47,0 & 0,91 & 18 & 58,1 & 35 & 53,0 & 0,64 \\
\hline & CT & 7 & 41,2 & 33 & 39,8 & $0,20^{*}$ & 10 & 32,2 & 28 & 42,4 & 0.34 \\
\hline & $\mathrm{T}$ & 0 & 0,0 & 11 & 13,2 & & 3 & 9,7 & 3 & 4,6 & $0,38^{*}$ \\
\hline \multirow[t]{4}{*}{ D543N } & G & 31 & 91,2 & 159 & 95,8 & 0,23 & 60 & 96,8 & 118 & 89,4 & 0,08 \\
\hline & A & 3 & 8,8 & 7 & 4,2 & & 2 & 3,2 & 14 & 10,6 & \\
\hline & GG & 14 & 82,4 & 76 & 91,6 & $0,38^{*}$ & 29 & 93,5 & 52 & 78,8 & 0,07 \\
\hline & GA & 3 & 17,6 & 7 & 8,4 & & 2 & 6,5 & 14 & 21,2 & \\
\hline \multirow[t]{5}{*}{$1729+55$ del 4} & +TGTG & 20 & 58,8 & 79 & 58,1 & 0,94 & 37 & 63,8 & 67 & 57,8 & 0,45 \\
\hline & -TGTG & 14 & 41,2 & 57 & 41,9 & & 21 & 36,2 & 49 & 42,2 & \\
\hline & ++TGTG & 4 & 23,5 & 20 & 29,4 & $0,77^{*}$ & 10 & 34,5 & 16 & 27,6 & 0,51 \\
\hline & +-TGTG & 12 & 70,6 & 39 & 57,4 & 0,32 & 17 & 58,6 & 35 & 60,3 & 0,88 \\
\hline & -TGTG & 1 & 5,9 & 9 & 13,2 & $0,68^{*}$ & 2 & 6,9 & 7 & 12,1 & $0,71^{*}$ \\
\hline
\end{tabular}

*Teste de Fisher. Genótipos: cálculo do qui-quadrado comparativo de cada genótipo com soma dos outros do mesmo polimorfismo.

TABELA 5 - Distribuição dos pacientes reacionais estudados quanto às freqüências genotípicas de cada polimorfismo e o tipo reacional.

\begin{tabular}{|c|c|c|c|c|c|c|c|c|c|c|c|}
\hline \multirow[b]{3}{*}{ Polimorfismo } & \multirow[b]{3}{*}{ Genótipo } & \multicolumn{4}{|c|}{ Reação Tipo I } & \multirow[b]{3}{*}{$p$} & \multicolumn{4}{|c|}{ Reação Tipo Ii } & \multirow[b]{3}{*}{$p$} \\
\hline & & \multicolumn{2}{|c|}{$\operatorname{sim}$} & \multicolumn{2}{|c|}{ não } & & \multicolumn{2}{|c|}{$\operatorname{sim}$} & \multicolumn{2}{|c|}{ não } & \\
\hline & & $\overline{\mathrm{n}^{\mathrm{o}}}$ & $\%$ & $\mathrm{n}^{\mathrm{o}}$ & $\%$ & & $\mathrm{n}^{\mathrm{o}}$ & $\%$ & $\mathrm{n}^{\mathrm{o}}$ & $\%$ & \\
\hline \multirow[t]{3}{*}{$274 \mathrm{C} / \mathrm{T}$} & $\mathrm{CC}$ & 87 & 52,4 & 15 & 48,4 & 0,68 & 25 & 50,0 & 77 & 52,4 & 0,77 \\
\hline & $\mathrm{CT}$ & 68 & 41,0 & 10 & 32,2 & 0,36 & 17 & 34,0 & 61 & 41,5 & 0,35 \\
\hline & $\pi$ & 11 & 6,6 & 6 & 19,4 & $0,03^{*}$ & 8 & 16,0 & 9 & 6,1 & 0,04 \\
\hline \multirow[t]{2}{*}{ D543N } & GG & 144 & 86,7 & 27 & 87,1 & $0,61^{*}$ & 44 & 88,0 & 127 & 86,4 & 0,77 \\
\hline & GA & 22 & 13,3 & 4 & 12,9 & & 6 & 12,0 & 20 & 13,6 & \\
\hline \multirow[t]{3}{*}{$1729+55$ del 4} & ++TGTG & 44 & 30,1 & 6 & 23,1 & 0,46 & 12 & 28,6 & 38 & 29,2 & 0,93 \\
\hline & +-TGTG & 85 & 58,2 & 18 & 69,2 & 0,29 & 24 & 57,1 & 79 & 60,8 & 0,68 \\
\hline & —TGTG & 17 & 11,7 & 2 & 7,7 & 0,42 & 6 & 14,3 & 13 & 10,0 & $0,30^{*}$ \\
\hline
\end{tabular}

${ }^{*}$ Teste de Fisher.

Genótipos: cálculo do qui-quadrado comparativo de cada genótipo com soma dos outros do mesmo polimorfismo. 


\section{DISCUSSÃo}

O estudo da associação entre três polimorfismos do gene NRAMP1 e as reações hansênicas em pacientes multibacilares e paucibacilares baseou-se nas evidências de que a susceptibilidade, resistência e apresentações clínicas da hanseníase poderem ser atribuídas aos polimorfismos genéticos ${ }^{6,9,14,24}$. No entanto, não se localizou qualquer publicação dessa associação com as reações hansênicas, daí a importância desta pesquisa.

No presente estudo, ao relacionar as frequências alélicas e genotípicas dos polimorfismos da NRAMP1 com os resultados da baciloscopia inicial dos pacientes, que espelha a multiplicação do Mycobacterium leprae, não se encontrou associação significante. $\mathrm{O}$ mesmo foi observado também em relação ao sexo e fototipo.

Uma resposta imune inata efetiva em combinação com a baixa virulência do Mycobacterium leprae está associada à resistência para o desenvolvimento da hanseníase ${ }^{3}$. Desse processo, participam os receptores de reconhecimento de padrões, como os Toll-like (TLRs), que são essenciais para a identificação de patógenos pelos macrófagos e pelas células dendríticas, os quais induzem à resposta imune Th1 ou Th2, que pode ser influenciada pela expressão de determinados alelos do gene NRAMP $1^{23}$.

A proteína NRAMP1 está localizada no compartimento endossômico ou lisossômico maduro de macrófagos ativados pela presença da $M$. leprae e determina a liberação do sinal intracelular para a migração de endossomos ou lisossomos e fusão destes no mecanismo de regulação da multiplicação bacteriana. Genótipos selvagens da NRAMP1 promovem migração rápida dessas vesículas do sistema de Golgi para a região celular contendo fagossomos com Mycobacterium leprae, diferente do que ocorre nos genótipos mutantes ${ }^{11}$. Essa ação dos genótipos da NRAMP1 depende também do equilíbrio iônico e do transporte de cátions divalentes $\left(\mathrm{Fe}^{2+}, \mathrm{Zn}^{2+}\right.$ e $\mathrm{Mn}^{2+}$ ), para manutenção do $\mathrm{pH}$ intracelular que assegura a ação da peptidase para processamento antigênico endossomal, impedindo o desenvolvimento e a multiplicação do Mycobacterium leprae no macrófago $^{11,15,23,24}$.

Defeitos na produção da proteína codificada pelo NRAMP1, decorrentes da ação de determinados alelos mutantes, podem levar a uma síntese protéica inadequada e, consequentemente, à replicação bacteriana por falha da atividade macrofágica. Esses achados foram confirmados por Abel e cols ${ }^{6}$ e Meisner e cols ${ }^{20}$ ao identificarem, em população vietnamita, africana e indiana, polimorfismos envolvidos na hanseníase, dentre eles o $274 \mathrm{C} / \mathrm{T}$, o D543N e o $1729+55$ del 4 .

Pode-se afirmar que ogene mutante suprime a ativação macrofágica, facilitando a multiplicação bacteriana e, consequentemente, favorecendo a forma multibacilar o que foi observado por Bellamy e cols ${ }^{25}$ ao estudarem a tuberculose. Analogamente, indivíduos com composição gênica selvagem teriam maior atividade dos macrófagos, o que dificultaria a reprodução bacteriana, levando à forma paucibacilar.

No entanto, essa lógica parte da premissa de que a multiplicação bacteriana estaria relacionada à composição gênica da NRAMP1, independente da ação de outros fatores, o que não tem sido corroborado por Abel e cols ${ }^{6}$ ao alertarem que a composição gênica interfere sobre a susceptibilidade à infecção bacteriana, mas não a sua progressão.
Na presente pesquisa, não foi observado o predomínio do genótipo heterozigótico +TGTG/-TGTG do polimorfismo $1729+55$ del4 nos multibacilares, como verificaram Meisner e cols ${ }^{20}$, ao estudarem hanseníase na população africana.

Quando se analisou a associação entre a composição genotípica dos polimorfismos 274C/T, D543N e 1729+55del4e da NRAMP1 com as reações hansênicas tipo I e tipo II, independente das formas multibacilar ou paucibacilar, foi possível identificar diferença significante. O genótipo mutante TT do polimorfismo 274C/T associou-se à presença da reação tipo II, restrita à forma multibacilar, e ausência da reação tipo I.

Soo e cols ${ }^{24}$ testaram a hipótese de que a NRAMP1 influencia o padrão de resposta imunológica, estudando indivíduos com leishmaniose, e concluíram que os alelos selvagens da NRAMP1 elicitavam predominantemente linfócitos T helper I, ou seja, reação Th1, enquanto que os alelos mutantes induziam reações Th2.

Para investigar a influência da NRAMP1 na resposta imunológica adquirida contra a Mycobacterium leprae, Alcais e $\operatorname{cols}^{26}$ realizaram análise de ligação entre a região genômica NRAMP1 e a intensidade da reação de Mitsuda em 118 componentes de 20 famílias nucleares com hanseníase, no Vietnã, ao identificarem essa associação, concluíram que a NRAMP1 influencia a diferenciação das reações imunológicas Th1/Th2.

Scollard e cols ${ }^{3}$, em revisão de artigos publicados entre 1990 e 2006, sobre os diversos aspectos da hanseníase, consideraram importante a associação entre as formas mais graves e o padrão de citocinas Th2, ficando as formas leves relacionadas ao padrão Th1.

Essas comprovações parecem reforçar os resultados da presente pesquisa, os quais acrescentaram ao conhecimento da hanseníase a associação entre os padrões de citocinas e o genótipo TT do polimorfismo $274 \mathrm{C} / \mathrm{T}$. Esse resultado permitiu levantar a hipótese de que a composição gênica mantém uma relação mais estreita com a reação imunológica do que com a multiplicação bacteriana, representada pela baciloscopia.

Concluindo, no presente estudo, os achados permitiram enunciar a hipótese de que a composição gênica parece estar mais relacionada à reação imunológica do que à multiplicação bacteriana.

\section{AGRADECIMENTOS}

Aos colegas dermatologistas e demais funcionários do CISAM e da policlínica Lessa de Andrade e aos pacientes que, num gesto de desprendimento, concordaram em participar do estudo

\section{CONFLITO DE INTERESSE}

Os autores declaram não haver nenhum tipo de conflito de interesse no desenvolvimento do estudo.

\section{REFERÊNCIAS}

1. Moraes MO, Cardoso CC, Vanderborght PR, Pacheco AG. Genetics of host response in leprosy. Lepr Rev 2006;77:189-202.

2. WHO. World Health Organization. Weekly epidemiological record. No. 25, 2007, 82, 225-232 Geneva; 2007.

3. Scollard DM, Adams LB, Gillis TP, Krahenbuhl JL, Truman RW, Williams DL. The continuing challenges of leprosy. Clin Microbiol Rev 2006;19:338-381. 
4. Andrade ARC, Lehman LF, Schureuder PAM. Como reconhecer e tratar reações hansênicas. Secretaria de Estado de Saúde de Minas Gerais. Belo Horizonte; 2005 .

5. Brito MFM.Associação entre reação hansênica após tratamento (Poliquimioterapia Multibacilar - PQT/MB) e a carga bacilar através da detecção de anticorpos IgM (Imunoglobulina M) contra PGL-1(Glicolípide Fenólico 1) do Mycobacterium leprae. Tese. Recife, PE; 2008.

6. Abel L, Sanchez F, Obert J, Thuc LV, Skamene E, Lagrange PH, et al. Susceptibility to leprosy is linked to the human NRAMP1 gene. Infect Dis 1998; 177: 133-145.

7. Beiguelman B. Genética e hanseníase. Cien Saude Colet 2002; 7:117-128.

8. Alcaïs A, Mira M, Casanova JL, Schurr E, Abel L. Genetic dissection of immunity in leprosy. Curr Opin Immunol 2005; 17:44-48.

9. Ferreira FR, Goulart LR, Silva HD, Goulart IMB. Susceptibility to Leprosy May Be Conditioned by an Interaction between the NRAMP1 Promoter Polymorphisms and the Lepromin Response. Int J Lepr Other Mycobact Dis 2004; 72: 457-467.

10. Prevedello FC, Mira MT. Hanseníase: uma doença genética? An Bras Dermatol 2007; 82:451-459.

11. Blackwell JM, Searle S, Goswami T, Miller EN. Understanding the multiple functions of Nramp1. Microbes and Infect 2000; 2: 317-321.

12. Canonne-Hergaux F, Gruenheid S, Govoni G, Gros P. The Nramp1 Protein and Its Role in Resistance to Infection and Macrophage Function. Proceedings of the Association of American Physicians 1999; 111: 283-289.

13. Marquet S, Lepage P, Hudson TJ, Musser JM, Schurr E. Complete nucleotide sequence and genomic structure of the human NRAMP1 gene region on Chromosome region 2q35. Mamm Genome 2000; 11:755-62.

14. Mira MT, Alcais A, Van Thuc N, Thai VH, Huong NT, Ba NN, et al. Chromosome $6 q 25$ is linked to susceptibility to leprosy in a Vietnamese population. Nat Genet 2003;33:412-415.

15. Biggs TE, Baker ST, Botham MS, Dhital A, Barton CH. Nramp1 modulates iron homoeostasis in vivo and in vitro: evidence for a role in cellular iron release involving de-acidification of intracellular vesicles. Eur J Immunol 2001;31:2060-2070.

16. Nevo Y, Nelson N. The NRAMP family of metal-ion transporters. Biochimica et Biophysica Acta (BBA) - Molecular Cell Research 2006; 1763 : 609-620.

17. Blackwell JM, Searle S. Genetic regulation of macrophage activation: understanding the function of Nramp1 (= Ity/Lsh/Bcg). Immunol Lett 1999; 65: 73-80.

18. Lam-Yuk-Tseung S, Picard V, Gros P. Identification of a Tyrosine-based Motif (YGSI) in the Amino Terminus of Nramp1 (Slc11a1) That Is Important for Lysosomal Targeting. J Biol Chem 2006; 281: 31677-31688.

19. Liu Jing T, Fujiwara M, Buu NT, Sánchez FO, Cellier M, Paradis AJ, et al. Identification of Polymorphisms and Sequence Variants in the Human Homologue of the Mouse Natural Resistance-Associated Macrophage Protein Gene. Am J Hum Genet 1995; 56: 845-853.

20. Meisner SJ, Mucklow S, Warner G, Sow SO, Lienhardt C, Hill AVS. Association of NRAMP1 Polymorphism with leprosy type but not susceptibility to leprosy per se in west Africans. Am J Trop Med Hyg 2001; 65: 733-735.

21. Ridley DS, Jopling WH. Classification of leprosy according to immunity: a fivegroup system. Int J Lepr Other Mycobact Dis 1966; 34:255-273.

22. Fitzpatrick, TB. Soleil et peau. J Med Esthet $1975 ; 2: 33034$.

23. Brightbill HD, Libraty DH, Krutzik SR, Yang RB, Belisle JT, Bleharski JR, et al. Host defense mechanisms triggered by microbial lipoproteins through toll-like receptors. Science 1999;285:732-736.

24. Soo SS, Villarreal-Ramos B, Anjam Khan CM, Hormaeche CE, Blackwell JM. Genetic Control of Immune Response to Recombinant Antigens Carried by an Attenuated Salmonella typhimurium Vaccine Strain: Nramp1 Influences T-Helper Subset Responses and Protection against Leishmanial Challenge Infect Immun 1998; 66:1910-1917.

25. Bellamy R, Ruwende C, Corrah T, McAdam KP, Whittle HC, Hill AV. Variations in the NRAMP1 gene and susceptibility to tuberculosis in West Africans. N Engl J Med 1998;338:640-644.

26. Alcais A, Sanchez FO, Thunc NV, Lap VD, Oberti J, Lagrange PH, et al. Granulomatous reaction to intradermal injection of lepromin (Mitsuda reaction) is linked to the human NRAMP1 gene in Vietnamese leprosy sibships. J infect Dis 2000; 181: 302-308. 